\title{
KAJIAN DONGKRAK HIDROLIK BOTOL KAPASITAS 2 TON TERHADAP PENGARUH VARIASI POSISI PEMASANGAN MANOMETER, SAE OLI DAN JARAK LANGKAH PEMOMPAAN
}

\author{
Joko Yunianto Prihatin \\ Program Studi Teknik Mesin \\ Akademi Teknologi Warga Surakarta \\ Email: joko_ype@yahoo.com \\ Heri Kustanto \\ Program Studi Teknik Mesin, Teknik Elektro \\ Akademi Teknologi Warga Surakarta \\ Email: jokoyp.atw@gmail.com \\ Slamet Pambudi \\ Program Studi Teknik Mesin, Teknik Elektro \\ Akademi Teknologi Warga Surakarta \\ Email: pambudi0909@gmail.com
}

\begin{abstract}
ABSTRAK
Dongkrak hidrolik merupakan peralatan pendukung yang berfungsi untuk membantu mengangkat beberapa bagian dari kendaraan tersebut membantu kinerja manusia. Prinsip kerja dongkrak ini mengacu hukum pascal berkaitan kesetimbangan tekanan fluida pada pipa. Dewasa ini terdapat permasalahan pada dongkrak hidrolik botol tersebut diantaranya dongkrak macet, pemompaan cukup berat saat digunakan, tidak kuat menahan beban. Sehingga pemakaian di industri menjadi banyak biayanya dan waktunya. Berdasarkan permasalahan diatas, maka peneliti mengambil hipotesis bahwa bisa menyelesaikannya dengan menentukan sudut pengamatan utamanya pada pengaruh variasi posisi pemasangan manometer, jenis SAE oli yang dipakai dan jarak pemompaan. Penelitian ini diterapkan guna menganalisa dari hasil pengujian kemampuan tekannya dan volume bocornya ketika berbeban. Analisa data yang diterapkan adalah sastistik taguchi L4 3 faktor 2 level skala pendekatan. Kajian ini menghasilkan nilai kekuatan angkat optimal dari variasi tersebut adalah sebesar rerata $78 \mathrm{~kg} / \mathrm{cm}^{2}$. Sedangkan nilai komposisi pertama yaitu pada posisi pemasangan manometer $2 \mathrm{~cm}$, SAE oli 10 dengan jarak pemompaan $120 \mathrm{~mm}$ mampu menghasilkan nilai kekuatan angkat yang optimal, sehingga efektif dalam penggunaannya.
\end{abstract}

Kata kunci: dongkrak botol, hidrolik.

\begin{abstract}
Hydraulic Jack 2 ton are human helper attachment to lifting and loading the material use fluid hydraulic system. All of the Industry today has main trobble in lifter process. There are was broken, hard to pump, and loss power. The manufacturing in industry would be more time lost and more cost. According there are trobble happen, in this riset are trying to solved with choose factor variant analysis. They are manometer distance of assembling factor, oil sae used factor, distance of the pumping process factor. All of the factor hass 2 level, and respon target in this riset are tighten press and leak flow. To analysed and discused are using taguchi statistic with L4 array orthogonal with 2 level. Result of this riset are tighten press optimum reach $78 \mathrm{~kg} / \mathrm{cm}^{2}$ in first composition. They are manometer distance of assemble factor at $2 \mathrm{~cm}$, oil sae use factor at 10, distance of the pumping process factor at $120 \mathrm{~mm}$.
\end{abstract}

Keywords: hydraulic jack, tighten press.

\section{PENDAHULUAN}

Dongkrak merupakan salah satu pesawat pengangkat yang digunakan untuk mengangkat beban ke posisi yang dikehendaki dengan gaya yang kecil(1). Dongkrak hidrolik mengaplikasi fluida untuk menghasilkan tekanan yang diperlukan untuk pengangkatan, daya yang dihasilkan jauh lebih besar dan tenaga yang dibutuhkan untuk pengoprasian lebih sedikit dibandingkan dongkrak mekanik(3). 
Dewasa ini terdapat permasalahan pada dongkrak hidrolik botol tersebut diantaranya dongkrak macet, pemompaan cukup berat saat digunakan, tidak kuat menahan beban(2). Sehingga hal tersebut sangat mengganggu manusia dalam mengoperasikan dongkrak tersebut.

Berdasarkan permasalahan diatas, maka peneliti mengambil hipotesis utamanya dengan menentukan sudut pengamatan utamanya pada faktor pengaruh variasi posisi pemasangan manometer, jenis SAE oli yang dipakai dan jarak pemompaan. Penelitian ini diterapkan guna menganalisa dari hasil pengujian kemampuan tekannya dan volume bocornya ketika berbeban. Analisa data yang paling ekonomis terhadap biaya dan hasil yang diperoleh adalah taguchi(4), sehingga diterapkanya statistik taguchi L4 dengan 3 faktor dan 2 level skala pendekatan.

Bertitik tolak dari dasar permasalahan yang diketahui di atas, maka penelitian ini dapat dirumuskan antara lain:

a. Berapa nilai kekuatan angkat optimal dari variasi tersebut?

b. Berapa saja nilai komposisi variasi posisi pemasangan manometer, jenis SAE oli yang dipakai dan jarak pemompaan yang menghasilkan nilai kekuatan angkat yang optimal.?
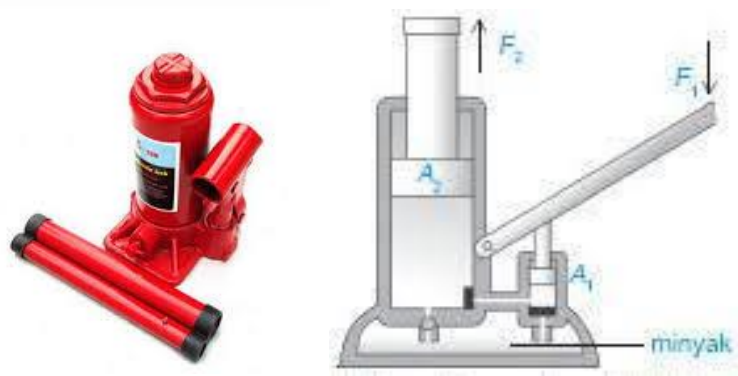

Gambar 1. Dongkrak Hidrolik Botol 2 Ton

\section{METODOLOGI PENELITIAN}

Didalam pelaksanaan penelitian terhadap kemampuan dongkrak hidrolik ini, penulis menerapkan tahapan secara sistematis sebagai berikut :

a. Survey literatur, dan standarisasi pabrik dongkrak hidrolik 2 ton

b. Survey aplikasi penggunaan dongkrak hidrolik 2 ton terkait dengan kemampuan tekan dan bocor oli.

c. Penentuan desain eksperimen (variasi jarak pemasangan manometer, jenis SAE oli dan jarak langkah pemompaan).

d. Pembuatan konstruksi dongkrak hidrolik sesuai desain eksperimen.

e. Pengujian dan pengumpulan data Kuat tekan $\mathrm{Kg} / \mathrm{cm} 2$ dan bocor oli cc/mnt.

f. Pengolahan dan analisis data menggunakan statistik taguchi.

g. Pembahasan dan penentuan kesimpulan komposisi optimal.

Peralatan dan bahan yang digunakan dalam penelitian ini adalah dongkrak hidrolik botol kapasitas 2 ton, manometer, vernier kaliper, Kunci Inggris, Tang, Obeng minus dan plus 10mm, Ragum, Mesin Bor, Las Kuningan, Nepel, Kunci Ring dan Pas 1 Set, Oli SAE, Stop whatch, Beban pemberat.

Tabel 1. Variabel bebas pengujian dongkrak hidrolik 2 ton

\begin{tabular}{cccc}
\hline No & Faktor & Level 1 & Level 2 \\
\hline & Variasi posisi pemasangan manometer (cm dari piston & & \\
1 & ungkit) & 2 & 8 \\
2 & Jenis SAE oli & 10 & 20 \\
3 & Jarak Pemompaan & 120 & 70 \\
\hline
\end{tabular}

Tabel 1 diatas menjelaskan penentuan variable bebas yang digunakan dalam penelitian dongkrak hidrolik ini.Variabel Terikat (Dependent Variable) : pada penelitian ini dititikberatkan pada variabel yang berpengaruh terhadap kemampuan mengangkat dan volume bocornya yang optimal. Disamping itu penerapan analisa statistik pada penelitian ini adalah taguchi dengan desain eksperimen array orthogonal L4 seperti dijelaskan pada tabel 2 dibawah ini. 
Tabel 2. Desain eksperimen array orthogonal 14

\begin{tabular}{cccc}
\hline No & $\boldsymbol{1}$ & $\mathbf{2}$ & $\mathbf{3}$ \\
\hline 1 & 1 & 1 & 1 \\
2 & 1 & 2 & 2 \\
3 & 2 & 1 & 2 \\
4 & 2 & 2 & 1 \\
\hline
\end{tabular}

Selanjutnya dilakukan pembuatan konstruksi dongkrak hidrolik dengan penyesuaian ukuran dan perakitan sesuai dijelaskan pada gambar 2 dibawah. Kemudian dilakukan pengujian pada beban kosong dan berbeban secara bertahap.
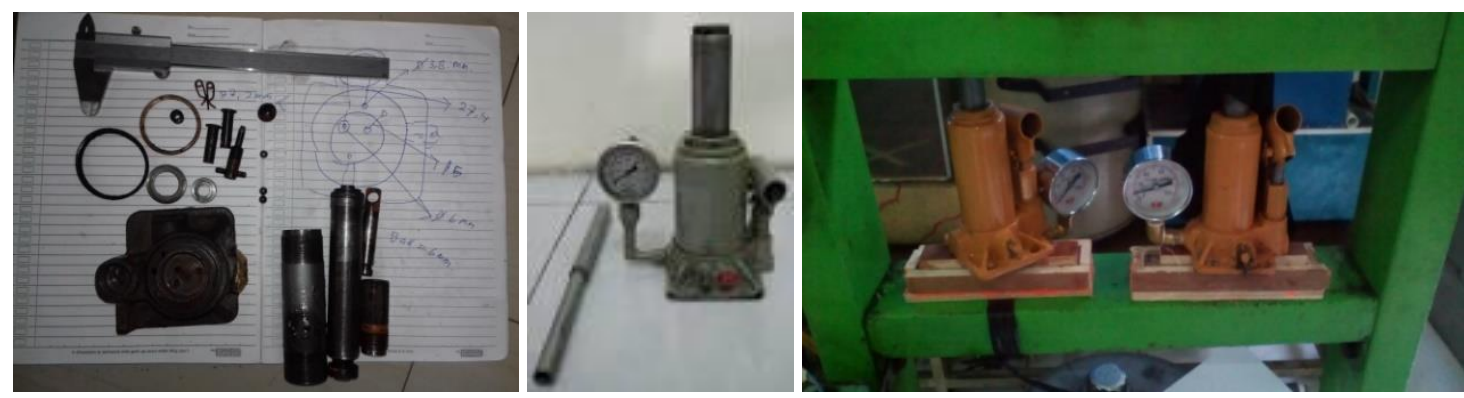

Gambar 2. Penyesuaian Dimensi Dan Bentuk Komponen Dongkrak, Dongkrak Rakitan, Pengujian Berbeban

\section{HASIL DAN PEMBAHASAN}

Hasil pengujian diambil dari hasil kombinasi atau variasi yang dilakukan dari ke 3 variasi terhadap 2 level dan masing-masing dilakukan 3 kali. Maka untuk keperluan pengujian tersebut diperlukan sedikitnya 12 sampel tiap responnya. Data kekuatan tekan dongkrak hidrolik dan data kebocoran oli hidrolik diambil sebanyak 3 kali dengan selisih antar waktu 10 menit. Selanjutnya dihitung nilai reratanya dan dilanjutkan menghitung SNR (Signal to Noise Ratio) berdasarkan kualitasnya. Kualitas kekuatan tekan semakin besar adalah semakin baik, sehingga menggunakan persamaan SNR LTB (Larger The Better). Seperti dijelaskan pada persamaan berikut ini :

$\eta=10 \log _{10}\left[\frac{\mu^{2}}{\sigma^{2}}\right]$

Nilai bocor aliran oli semakin sedikit adalah semakin baik, sehingga menggunakan persamaan SNR STB (Smaller The Better). Seperti dijelaskan pada persamaan berikut ini :

$\eta=-10 \log _{10}\left[\frac{1}{n} \sum_{i=1}^{n} y i^{2}\right]$

Tabel 3. Hasil kuat tekan dongkrak hidrolik (ltb-kg/cm²) dan debit bocor oli (stb-cc/mnt)

\begin{tabular}{|c|c|c|c|c|c|c|c|c|c|c|c|c|c|}
\hline \multirow[t]{2}{*}{ No } & \multicolumn{3}{|c|}{ Faktor } & \multicolumn{5}{|c|}{ Kekuatan Tekan (LTB-Kg/cm $\left.{ }^{2}\right)$} & \multicolumn{5}{|c|}{ Debit Bocor Oli (STB-cc/mnt) } \\
\hline & 1 & 2 & 3 & $1 x$ & $2 x$ & $3 x$ & Rerata & SNR & $1 x$ & $2 x$ & $3 x$ & Rerata & SNR \\
\hline 1 & 1 & 1 & 1 & 78 & 77 & 79 & 78.00 & 37.84 & 10 & 11 & 10 & 10.33 & 20.26 \\
\hline 2 & 1 & 2 & 2 & 67 & 65 & 66 & 66.00 & 36.39 & 9 & 10 & 10 & 9.67 & 19.67 \\
\hline 3 & 2 & 1 & 2 & 60 & 64 & 61 & 61.67 & 35.79 & 8 & 9 & 9 & 8.67 & 18.72 \\
\hline 4 & 2 & 2 & 1 & 70 & 73 & 74 & 72.33 & 37.18 & 8 & 8 & 9 & 8.33 & 18.38 \\
\hline
\end{tabular}

Tabel diatas menjelaskan bahwa rerata kekuatan tekan dongkrak tersebut mencapai maksimal pada komposisi pertama posisi pemasangan manometer $2 \mathrm{~cm}$, SAE oli 10 dengan jarak pemompaan $120 \mathrm{~mm}$. Kuat tekan maksimal yang dihasilkan sebesar $37,84 \mathrm{Kg} / \mathrm{cm}^{2}$ pada komposisi pertama, dan minimal $35,79 \mathrm{Kg} / \mathrm{cm}^{2}$ pada komposisi ketiga. Dan rerata kebocoran oli dongkrak tersebut mencapai minimal pada komposisi keempat posisi pemasangan manometer $8 \mathrm{~cm}$, SAE oli 20 dengan jarak pemompaan $120 \mathrm{~mm}$. 
kebocoran oli minimal yang dihasilkan sebesar 18,38cc/mnt pada komposisi keempat, dan maksimal 20,26cc/mnt pada komposisi pertama.

Dari hasil pengujian kuat tekan dan debit bocor oli hidrolik tersebut, dapat diketahui nilai pengaruhnya antar masing - masing faktor menggunakan persamaan berikut ini :

Efek faktor terdapat nilai SNR $=\frac{1}{a}\left(\sum \eta_{0}\right)$

Tabel 4. Efek tiap faktor respon kuat tekan dan debit bocor oli dongkrak hidrolik

\begin{tabular}{ccccccc}
\hline Keterangan & \multicolumn{3}{c}{ Kuat Tekan } & \multicolumn{3}{c}{ Debit Bocor Oli } \\
\cline { 2 - 6 } & $\mathbf{1}$ & $\mathbf{2}$ & $\mathbf{3}$ & $\mathbf{1}$ & $\mathbf{2}$ & $\mathbf{3}$ \\
\hline Level 1 & 74.23 & 73.63 & 75.02 & 39.93 & 38.98 & 38.64 \\
Level 2 & 72.97 & 73.57 & 72.18 & 37.09 & 38.05 & 38.39 \\
Maksimal & 74.2293 & 73.6318 & 75.0199 & 39.9319 & 38.9752 & 38.6356 \\
Minimal & 72.9707 & 73.5683 & 72.1802 & 37.0932 & 38.0498 & 38.3894 \\
Selisih Level & 1.2586 & 0.0634 & 2.8397 & 2.8387 & 0.9254 & 0.2461 \\
Komposisi Optimal & 1 & 1 & 1 & 1 & 1 & 1 \\
Rangking & 2 & 3 & 1 & 1 & 2 & 3 \\
\hline
\end{tabular}

Tabel diatas menjelaskan bahwa nilai kuat tekan hidrolik dongkrak optimal berada pada komposisi pertama, yaitu posisi pemasangan manometer $2 \mathrm{~cm}$, SAE oli 10 dengan jarak pemompaan 120mm. Sedangkan faktor jarak pemompaan $(2,8397)$ memiliki kontribusi terhadap kuat tekan yang paling besar, dan faktor penggunaan jenis SAE oli memiliki kontribusi terkecil $(0,0634)$ setelah faktor jarak pemasangan manometer.

Tabel diatas juga menjelaskan bahwa nilai kebocoran hidrolik dongkrak optimal berada pada komposisi pertama, yaitu posisi pemasangan manometer $2 \mathrm{~cm}$, SAE oli 10 dengan jarak pemompaan $120 \mathrm{~mm}$. Sedangkan faktor jarak pemasangan manometer $(2,8387)$ memiliki kontribusi terhadap kebocoran yang paling besar, dan faktor jarak pemompaan $(0,2461)$ memiliki kontribusi terkecil setelah faktor penggunaan jenis SAE oli.

Berdasarkan tabel diatas sehingga dapat menjelaskan bahwa komposisi optimal berada pada komposisi pertama yaitu pada posisi pemasangan manometer $2 \mathrm{~cm}$, SAE oli 10 dengan jarak pemompaan $120 \mathrm{~mm}$. Sehingga nilai optimal kekuatan tekan yang dihasilkan kita ambil dari tabel 2 sebesar rerata $78 \mathrm{~kg} / \mathrm{cm}^{2}$ dan nilai bocor oli dongkrak sebesar rerata $10,55 \mathrm{cc} / \mathrm{mnt}$.

\section{KESIMPULAN}

Berdasarkan nilai analisis data hasil pengujian kuat tekan dan debit bocor oli dongkrak hidrolik tersebut terhadap tujuan dan rumusan penelitian ini, maka dapat diambil kesimpulan sebagai berikut :

a. Nilai kekuatan angkat optimal dari variasi tersebut adalah sebesar rerata $78 \mathrm{~kg} / \mathrm{cm}^{2}$.

b. Nilai komposisi pertama yaitu pada posisi pemasangan manometer $2 \mathrm{~cm}$, SAE oli 10 dengan jarak pemompaan $120 \mathrm{~mm}$ mampu menghasilkan nilai kekuatan angkat yang optimal

\section{UCAPAN TERIMA KASIH}

Ucapan Terima Kasih penulis panjatkan Atas rahmat dan karunia-Nya Tuhan Yang Maha Kuasa sehingga penelitian ini dapat diselesaikan dengan baik. Ucapan terima kasih penulis juga disampaikan kepada pengelola LPPM Akademi Teknologi Warga Surakarta atas kerja samanya dan dukungannya dalam pelaksanaan kegiatan publikasi karya ilmiah ini.

\section{DAFTAR PUSTAKA}

[1] Rio Manopo, dkk, 2013, Proses Produksi Alat Angkat Kendaraan Niaga Kapasitas 2Ton, Jurusan Teknik Mesin Universitas Sam Ratulangi, Manado.

[2] Sisyono, Drs., 1991, Dasar-dasar Hidrolik, Bandung : PPPGT Bandung.

[3] Wahyu Handoko, dkk, April, 2013, Rancang Bangun Power Pack untuk Aktuasi Dongkrak Hidrolik Buaya 1 Ton, Tugas Akhir D3 Teknik Mesin Universitas Diponegoro, Semarang.

[4] Widodo dkk, 2002 "Penerapan Prosedur Multiresponse Signal TO Noise untuk Mengoptimalkan Proses Pembuatan Genteng Press di KUPP MEKAR SARI MAKMUR SUKOHARJO”. 